NASA Technical Memorandum 83530

\title{
Laboratory Degradation of Kapton in a Low Energy Oxygen Ion Beam
}

Dale C. Ferguson

Lewis Research Center

Cleveland, Ohio

Prepared for the

Shuttle Environment and Operations Meeting sponsored by the American Institute of Aeronautics and Astronautics Washington, D.C., October 31-November 2, 1983 


\title{
LABORATORY OEGRADATION OF KAPTON IN A
}

LOW ENERGY OXYGEN ION BEAM

\author{
Dale C. Ferguson* \\ National Aeronautics and Space Administration \\ Lewls Research Center \\ Cleveland, Ohto 44135
}

\begin{abstract}
An atomic oxygen ion beam, accelerated from a tunable microwave resonant cavity, was used at Lewis Research Center to bombard samples of the widely used polyimide Kapton. The Kapton expertenced degradation and mass loss at high rates, which may be comparable to those found in Space Shuttle operations if the activation energy supplied by the beam enabled surface reactions with the ambient oxygen. The simulation reproduced the directionality (ram-wake dependence) of the degradation, the change in optical properties of the degraded material, and the structure seen in scanning electron micrographs of samples returned on the Shuttle. Trials with a substituted argon ion beam produced no rapid degradation. Energy Oispersive $X$-ray Analys is (EDAX) showed significant surface composition changes in all bombarded samples.

Mass loss rates and surface composition changes are discussed in terms of the possible oxidation chemistry of the interaction. Finally, the question of how the harmful degradation of materials in low earth orbit can be minimized is addressed.
\end{abstract}

\section{INTRODUCTION}

Kapton and other materials (such as carbon coatings and paints) undergo weight loss and surface degradation in low earth orbit (ref. 1). Kapton, a polyimide with wide applications in spacecraft technology, experiences surface roughening on micron length scales, a change in surface appearance from a glossy transparency to a milky translucence, a loss in weight, and changes in its optical properties. These changes, first noted on the early space shuttle flights (ref. 1), have important implications for conducting extended operations using Kapton in low earth orbit. Kapton has been used for thermal control coatings and electrical insulation, and has been proposed as a flexible substrate for large solar arrays because of its excellent temperature stablifty, extremely low surface conductivity and flexible strength. It is important to know the mechanism for deterioration in low earth orbit so that Kapton may be modifled, coated, or replaced with other materlals in critical applications.

It has been suggested that interaction with the residual atomic oxygen atmosphere is the mechanism of degradation (ref. 1). The major atmospheric constituent at Shuttle altitudes is atomic oxygen. Each atom of oxygen

\#physicist. 
impacts on an orbiting vehicle with an energy of about $8 \times 10^{-19} \mathrm{~J}(5 \mathrm{eV})$, equivalent to the impact energy of thermal atoms at about $60000 \mathrm{~K}$. High temperature oxidation, about which little is known, may then be the reaction leading to mass loss, change of surface properties, etc.

Though oxidation is a likely hypothesis as the mechanism of degradation, other possibilities may exist. The mass loss might be due to low energy sputtering, for example. It is well known that sputtering thresholds for metals seem to be higher than the impact energies of atoms and molecules in low earth orbit, but such thresholds have never been measured for complex organic materials. Also, chemical reactions with other species abundant in low earth orbit, such as molecular nitrogen, could not be excluded out of hand.

\section{GOALS AND APPROACH}

It is desirable to understand the mechanism of the orbital interaction of Kapton and other materials with atomic oxygen, to see whether the interaction is chemical or sputtering in nature, to determine reaction rates and temperature and energy dependences, to investigate the possibility of interfering with the interaction through the use of protective coatings or other materials and to develop techniques for testing materials before flight. At Lewis Research Center, it was decided to attempt the simulation of conditions in low earth orbit to investigate these matters. Since it is difficult to accelerate neutral atomic species to the energies seen in orbit, it was decided to use accelerated ions in the Lewis simulation. It is clear from work on sputtering (ref. 2) that charge exchange with the surface may occur long before the momentum exchange, so that by the time the reaction energy is imparted by the incoming ions, they may be identical to neutral atoms for chemical purposes.

Thus, an attempt was made to simulate the impact conditions in low earth orbit by acceleration and impact of oxygen and other ions. Then, the exposed specimens were analyzed and the results compared with those reported from Shuttle flight experiments and other laboratory simulations. Reaction rates and surface compositions were found. Finally, an attempt was made to understand the laboratory results and see what light they might shed on the flight results and on the reaction mechanism, in order to simulate, understand, and suggest ways to control the reaction in low earth orbit.

\section{THE EXPERIMENT}

Figure 1 is a schematic drawing of the experiment setup. For the preliminary results reported here, a tunable microwave resonant cavity was used to dissociate and lonize technical grade ( 99.5 percent) oxygen gas. The gas was leaked into a glass container within the microwave cavity and after ionization, accelerated electrostatically to impact on samples of Kapton. The experiment was done in vacuum tank no. 8 of the Electric Propulsion Laboratory at Lewis Research Center. Tank no. 8 is a horizontal circular cylinder, about 1 meter in radius and 4 meters in length. Tank pressures during beam operation were maintained by diffusion pumps at about $1.3 \times 10^{-2} \mathrm{~Pa}\left(10^{-4}\right.$ torr), compared to about $1.3 \times 10^{-4} \mathrm{~Pa}\left(10^{-6}\right.$ torr) with the beam off. The he ip of Shigeo Nakanishi of the N.A.S.A. Lewis Electric Propulsion Technology Section was invaluable in obtaining the experimental results reported here. 
The microwave cavity used a maximum of $100 \mathrm{~W}$ of radiation at a frequency of $2450 \mathrm{MHz}$. The cavity was electrically blased at a voltage of around $+800 \mathrm{~V}$, and the accelerating grid (made of molybdenum, glass coated on one side) was blased to about $-200 \mathrm{~V}$. The fon beam produced was about $5 \mathrm{~cm}$ in diameter, diverging as it traversed the space between source and samples. A typical oxygen flow rate into the microwave cavity was about $4.2 \times 10^{-7} \mathrm{~m}^{3} / \mathrm{s}$ (25 standard cubic centimeters per minute).

The Kapton samples were supported by a strip heater with attached thermocouples. Source to sample distance was $10 \mathrm{~cm}$ for some trials and $23 \mathrm{~cm}$ for others. The samples analyzed in this paper were within $5 \mathrm{~cm}$ of the axial beam center. The plasma mean free path in all cases was longer than the source to sample distance. Deceleration of the beam was achieved for some samples by blasing the aluminum backing to retarding potentials of up to $+1000 \mathrm{~V}$. The heater strip was insulated from the samples by 2 layers of $2.5 \times 10^{-3} \mathrm{~cm}$ thick (1 mil) Kapton tape and from the tank wall by a fiberglass mounting beam. All wires in the cavity were covered with Tefion tubing to reduce glow discharges in the tenuous gas.

A retarding potential analyzer (RPA) which could be swung into and out of the beam was used to determine the beam current density. Typical RPA currents were $185 \mu A$, which divided by the RPA area of $13.4 \mathrm{~cm}^{2}$, gives an average central beam current density of about $14 \mu \mathrm{A} / \mathrm{cm}^{2}$. Spectroscopic analysis of the beam was done with a 0.5 meter Jarre 11-Ash spectrometer with $0.1 \wedge$ resolution. The spectrum shows that most of the beam consisted of singly ionized atomic oxygen, although lines of neutral atomic oxygen were prominent near the sample distance because of their greater radiative ilfetimes. Equilibrium floating potentials on the heater strip while the beam was in operation were measured on the thermocouple wires to be in the range of +400 to $+500 \mathrm{~V}$.

While the oxygen beam was operating, a faint white glow could be seen extending about $5 \mathrm{~mm}$ in front of impacted surfaces. Behind the sample holder, a distinct greenish tinge could be seen in the diffuse glow of the beam. The white glow can be attributed to continuum radiation from oxygen recombination at the surface. The green glow appears spectroscopically (ref. 3) to be from the first negative bands of $0 \%$, which one suspects is from ionization of the recombined oxygen by the impinging ion beam.

Table I gives the parameters of the Lewis preliminary feasiblitity studies. Fluxes were calculated from RPA currents, and estimated beam divergence and total fluence from fluxes and exposure times. In each case, the expected thermal flux of neutral oxygen is greater than the lon flux in the beam, and yet degradation occurred only in areas where the beam actually struck the samples. Thus, the impact energy must be important to the degradation.

\section{RESULTS AND ANALYSIS}

Visual inspection of the bombarded surfaces showed that where the oxygen beam had struck, the smooth, yellow transparent surface of the Kapton had changed to a milky yellow translucence. Argon-bombarded samples at the same low fluence showed no such change; only a thin transparent metalilic film which 
EDAX showed to be molybdenum sputtered from the uncoated side of the accelerator grid. Under oxygen bombardment, shadowed regions of the Kapton tape surrounding the sample holder showed no degradation, nor did areas outside of the beam. In one case $(11 / 24 / 82)$ the Kapton tape in the center of the beam showed a total loss of Kapton, leaving only the sticky sllicone adhesive. The aluminum backsides of argon-bombarded sample strips had a scorched, blackened appearance near the edges, which EDAX later showed to be thin molybdenum coatings, again presumed to be sputtered from the accelerator grid.

Under the scanning electron microscope, the oxygen bombarded samples showed a carpetlike texture, with structures about $1 \mu \mathrm{m}$ in size and smaller. These are quite similar in appearance to samples returned by STS filights (fig. 2 from ref. 4). By contrast, pristine samples and argon-bombarded samples of Kapton were smooth under all magnifications.

Also, under a scanning electron microscope (SEM), an indication was obtained that the surface conductivity of Kapton was changed after ion bombardment. Both oxygen and argon-bombarded samples retained their surface charge (as made vistble by changes in magnification) for much shorter times than did the pristine control sample. It is not clear if the change in surface conductivity is due to the presence of sputtered contaminants or whether it may be due in part to changes in surface composition.

Low energy EDAX analysis of the samples was undertaken with the valued assistance of Paul Aron of the N.A.S.A. Lewis Tribology Branch. The instrument used had a windowless detector, allowing very low energy electrons to be ut 11 ized. Although EDAX at high energies $\left(2.4 \times 10^{-15} \mathrm{~J}\right.$ or $\left.15 \mathrm{keV}\right)$ showed the presence of amounts of aluminum, silicon, and molybdenum in the bombarded samples (presumably sputtered from the accelerator grid and tank wall fixtures) and their absence in the pristine samples, it was of 11 imited usefulness in analysis of the change in surface composition of the Kapton. Pristine Kapton, being an extremely good insulator, will acquire a charge through loss of secondary electrons for incldent electron energies above about $2.4 \times 10^{-16} \mathrm{~J}$ or $1.5 \mathrm{keV}$. Thus, the pristine standard would see EDAX electrons of a different energy than those seen by the more conductive ion bombarded samples.

Furthermore, electrons of $2.4 \times 10^{-15} \mathrm{~J}$ (15 keV) energy have a mean free path in Kapton of about $6.4 \times 10^{-4} \mathrm{~cm}(0.25 \mathrm{mi1})$, making bulk composition and geometrical effects (due to the texture of the oxygen bombarded surface) important in the analysis. For these reasons, EDAX at incident energies of $1.6 \times 10^{-16} \mathrm{~J}(1.0 \mathrm{keV})$ was undertaken. At this energy, the mean free path of electrons in Kapton should be about $7.6 \times 10^{-5} \mathrm{~cm}(0.03 \mathrm{mi1})$, insuring that the true surface composition would be measured, allowing only for shadowing on the $x$-ray counts from textured surfaces.

Taking mass attenuation coefficients and fluorescence ylelds from Robinson (ref. 5), and assuming a 3 percent metallic mass fraction from sputtered metals, the relative $C, N$, and 0 abundances at the surface could be determined. Table II gives a summary of the present results on samples at different EDAX electron energies. There it can be seen that the composition measured with the $1.0 \mathrm{keV}$ energy is significantly different from the pristine Kapton used as a caltbration for both oxygen and argon-bombarded samples. 
These results are insensitive to errors in the total count rate, electron penetration depth, and percentage of metals assumed, largely because the penetration depth is so small that there is less than 20 percent absorption for X-rays from any species. The composition obtained from the EDAX analysis may be compared to that which would occur if pristine Kapton lost 40 percent of its carbon atoms (normalizing to $C, N$, and 0 only) of

$\begin{array}{cc}\text { Element } & \text { Percent } \\ \mathrm{C} & 59.4 \\ \mathrm{~N} & 10.1 \\ 0 & 30.5\end{array}$

suggesting that the major change in composition of the surface is a severe loss of carbon. Since the electron penetration depths at energies of $4 \mathrm{keV}$ and $15 \mathrm{keV}$ are so much larger, a loss of carbon only near the surface is also consistent with the measurements made at those energies.

Auger analysis of other samples done by $W$. Gordon and R. Hoffman of Case Western Reserve University and communicated to us before publication has confirmed these results for the case of oxygen bombardment (severe loss of carbon) but was quite varlable for argon-bombardment. It may be concluded that for the oxygen bombarded samples the surface has suffered a severe carbon loss, while for the argon-bombarded samples the situation is more complicated. For the argon-bombardment case, composition changes may be due to selective sputtering (ref. 6), while for oxygen bombardment beam deceleration may have made sputtering unlikely. Since chemical interaction is indicated at any rate as the source of surface damage in the oxygen case, the major chemical change appears to be oxidation of carbon on the surface, which then evolves as gaseous carbon monoxide or dioxide, leaving a carbon depleted surface. This hypothesis is consistent with the reported rapid loss of pure carbon coatings in LEO (ref. 3 ).

The surface of the oxygen bombarded samples became quite soft (easily scratched) with abraded sections losing their milky translucence and becoming yellow and transparent, much like the pristine samples. No visible amount of material was left on the scratching implement, implying that the change of optical properties was indicative only of a change in surface structure.

The indices of refraction of the samples were measured using ellipsometry. The ellipsometer used a He-Ne laser of wavelength $6328 \wedge$ and had a resolution of $\sim 0.1^{\circ}$ in polarizer and analyzer angle. Despite some difficulty in keeping the samples flat, repeatable measurements were obtained, with the following results: while the pristine samples were very similar in optical properties to the aluminum backing on the pristine sample (which proved to be coated by a thin film itself) the ion bombarded samples were significantly different. The real and imaginary parts of the index of refraction are given in Table III.

The variation with position on the argon-bombarded sample can be ascribed to variations in the amount of sputtered molybdenum on the surface at different points, position 2 closely resembling the apparent optical properties of the pristine sample. 
Although the samples were aluminum backed, the surfaces of the oxygen bombarded samples, and in particular of sample 2 , were quite opaque, and the optical measurements were thus probably not heavily influenced by the aluminum backing. These values are probably not intrinsic to oxidized Kapton itself, but are indicative of the values as changed by the surface structure, as discussed by Fenstermaker and McCrackin (ref. 8).

At the laser wavelength $(6328 \mathrm{~A})$ and $70^{\circ}$ angle of incidence used, there was no apparent specular reflection observed for sample 2 . The observed change in reflectance of the oxidized Kapton may be due to the peculiar surface structure seen in the SEM photos, which when disturbed by scratching the surface, reverts to the optical properties of smooth Kapton.

An attempt to calibrate the beam intensity by the changed optical properties of argon-bombarded samples, as described in Mirtich and Sovey (ref. 9), falled because of the thin sputtered molybdenum film deposited in the present experiment.

Mass loss from the Kapton films was evident from the complete loss of material in the beam center in one trial. An estimate, from the depth of material removed and the measured beam fluxes, of the mass loss rate from two of our trials is given in Table IV. The apparent mass loss rates seem much higher than those $\left(\sim 3.72 \times 10^{-24} \mathrm{~g} / 0\right.$ atom) seen in Shuttle experiments (ref. 10). It is possible that this may be due to reactions with thermal oxygen atoms and molecules in the tank, which had a much greater flux against the sample than did the lon beam. The absence of reactions outside of the beam area can be explained if the activation energy for the reactions is supplied only by the energetic ions in the beam. In Table $v$ are given calculated reaction rates per thermal collision in the tank, assuming the ideal gas law and pure oxygen at the tank pressure. These rates are consistent with those found on the Shuttle, and lend further credence to the hypothesis that the reaction seen in the lab is the same as that occurring in orbit.

\section{SUMMARY AND INTERPRETATION OF RESULTS}

The following aspects of the Shuttle returned samples were reproduced in the Lewis ion beam experiments:

(1) Visual appearance

(2) SEM surface structure

(3) Change from specular to diffuse reflection

(4) Directionality (ram dependence)

In addition, the mass loss is consistent with rates seen in orbit if ambient thermal gas in the experiment could share in the activation energy supplied by the beam. 
The following findings were new to this experiment, and suggest further tests on the Shuttle samples:

(1) Reduced scratch resistance of surface

(2) Loss of carbon from surfaces

(3) Enhanced surface conductivity

(4) Confirmation that chemistry is involved in surface structure changes

The structures seen on $0^{+}$bombarded Kapton surfaces seem to be responsible for the change in specular reflectivity. In addition, the loss of carbon suggests that the surface structure seen may be prouduced by oxygen preferentially attacking certain bonds in the palymer. The bonds which are probably attacked most readily are the $C-N$ bond $(E=3.2 \mathrm{eV}$ ), the $\mathrm{C}-\mathrm{O}$ bond $(E=3.7 \mathrm{eV})$, and the $C-C$ bond $(E=3.8 \mathrm{eV}$ ) (ref. 11), all with energies below the apparent impact energy of atomic oxygen in LEO. Breaking of the $C-N$ and C- 0 bonds breaks the polymer chain, weakening the materlal and allowing penetration of succeeding 0 atoms deeper into the plastic. Furthermore, succeeding breaks of the $\mathrm{C}-\mathrm{C}$ bonds can allow oxidation of the dangling carbon, leading to a volatile product and mass loss.

\section{CONCLUSIONS}

It is encouraging that this simulation of LEO conditions using $0^{+}$ion beams has succeeded in qualitatively reproducing all of the observed characteristics of the interaction of Kapton with the earth's atmosphere in Space Shuttle flights. Oxidation is undoubtedly responsible, as opposed to sputtering or reaction with other species, since simulation with $0^{+}$was successful, and high energy impact by an inert gas did not produce the observed characteristics of samples returned from orbit. It may be possible to test a variety of materials for reactivity and quantitative mass loss rates using $0^{+}$ion beams in the laboratory.

Regardless of the specific chemical reaction involved, it has already been found that other materials are minimally reactive or nonreactive (ref. 8). It may be possible to retain the desirable characteristics (radiation resistance, electrical resistance, strength, flexiblitity, and high temperature stability) of Kapton for use as a substrate by coating it with less reactive flims. Oxygen ion beam bombardment is a feasible method of testing such new materlals before using them in space. Much work remains to be done at Lewis and elsewhere in testing materials and understanding the reactions which take place.

\section{REFERENCES}

1. Leger, L.J.: Oxygen Atom Reaction with Shuttle Materials at Orbital Altitudes. NASA TM-58246, 1982.

2. Hagstrum, Homer D.: Low Energy De-Excitation and Neutralization Processes Near Surfaces. Inelastic Ion-Surface Collistons, N.H. Tolk. J.C. Tully, W. Helland, ed., Academic Press, 1977, pp. 1-25. 
3. Pearse, R. W. B.; and Gaydon, A. G.: The Identification of Molecular Spectra, Third ed. Chapman and Hall, 1963. Plate 7.

4. Leger, L. J.; et al.: Space Shuttle Preliminary Contamination Assessment from STS-1 and STS-2. Presented at the 12th Space Simulation Conference, (Pasadena, CA.), May 17-19, 1982.

5. Robinson, J.W., ed.: Handbook of Spectroscopy, Vo1. 1, CRC Press, 1974, pp. 28-229.

6. Banks, B. A.: Ion Beam Applications Research - a Summary of Lewis Research Center Programs. NASA TM-81721, 1981.

7. Leger, L.: Oxygen Atom Reaction with Shuttle Materials at Orbital Altitudes - Data and Experiment Status. AIAA Paper 83-0073, Jan. 1983.

8. Fenstermaker, C. A.; and McCrackin, F. L.: Errors Arising from Surface Roughness in Ellipsometric Measurement of the Refractive Index of a Surface. N.M. Bashara; ÂB. Buckikman and A.C. Ha 11, eds., Recent Developments in Ellipsometry, North Holland Publ. Co., 1969, p. 85-96.

9. Mirtich, Michael J.; and Sovey, James S.: Optical and Electrical Properties of Ion-beam-textured Kapton and Tefion. J. Vac. Sc1. Technol., vol. 15, no. 2, Mar./Apr. 1978, pp. 697-701.

10. Leger, L. J.: JSC STS-5 Experiments Results. Presented at the NASA Meeting on Evaluation of Oxygen Interaction with Materials, (Washington, D.C.), Mar. 14-15, 1983.

11. Billmeyer, Fred W.,: Textbook of Polymer Science, second ed. WileyInterscience, 1971 , p. 16. 


\begin{tabular}{|c|c|c|c|c|}
\hline 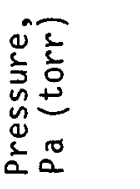 & 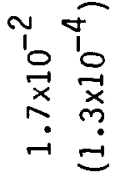 & 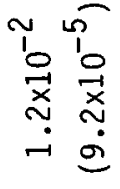 & 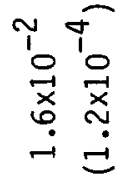 & $\begin{array}{ll}m & 0 \\
1 & 1 \\
0 & 1 \\
0 & 0 \\
x & x \\
0 & 0 \\
ن & 0 \\
\text { in } & 0\end{array}$ \\
\hline 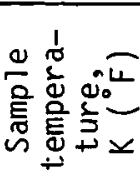 & 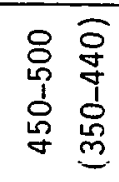 & $\begin{array}{ll}8 & 0 \\
\text { m } & \mathscr{8} \\
1 & 1 \\
\text { d } & 0 \\
\text { m } & 0\end{array}$ & $\underset{m}{\stackrel{8}{8}}$ & 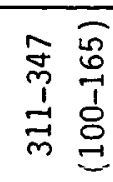 \\
\hline 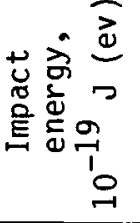 & $\begin{array}{l}8 \\
8 \\
m \\
7 \\
1 \\
0\end{array}$ & $\begin{array}{ll}0 & 0 \\
0 & 1 \\
1 & 1 \\
0 & 0\end{array}$ & $\begin{array}{l}\circ \\
\stackrel{\circ}{\mathrm{V}} \underset{\mathrm{V}}{\mathrm{V}}\end{array}$ & $\begin{array}{l}\mathbb{D} \\
\searrow \\
ન\end{array}$ \\
\hline 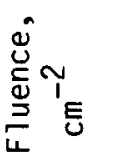 & 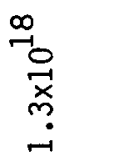 & $\begin{array}{l}\overrightarrow{7} \\
\stackrel{0}{0} \\
\vec{x} \\
\stackrel{-}{\sim}\end{array}$ & $\begin{array}{l}\text { न- } \\
\stackrel{1}{\circ} \\
\underset{x}{\dot{n}} \\
\dot{\sim}\end{array}$ & 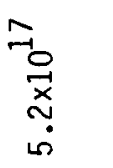 \\
\hline 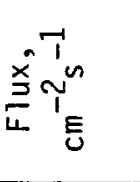 & 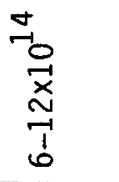 & 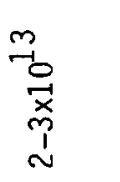 & $\begin{array}{l}m \\
\stackrel{m}{0} \\
\underset{x}{x} \\
\stackrel{1}{N}\end{array}$ & 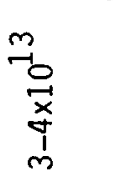 \\
\hline 두 & to & +o & to & ${ }^{+}<$ \\
\hline 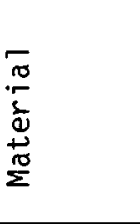 & 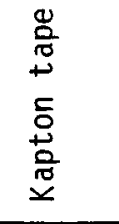 & 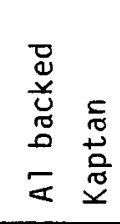 & 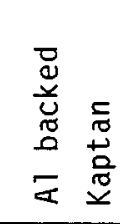 & 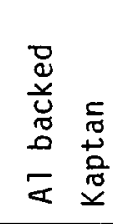 \\
\hline 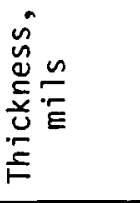 & $r$ & 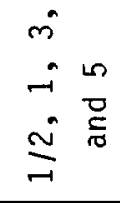 & 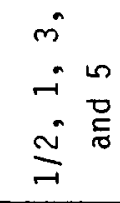 & 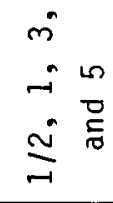 \\
\hline 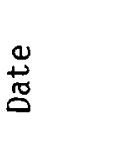 & 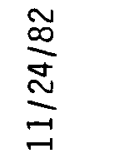 & $\frac{\tilde{\infty}}{\infty}$ & 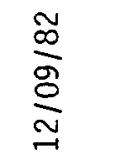 & $\underset{\sim}{\stackrel{\infty}{N}}$ \\
\hline
\end{tabular}


TABLE II. - PERCENTAGE BY WEIGHT OF ELEMENTS $C, N$, AND 0

[Assumes 3 percent metals, normalized to $\mathrm{C}+\mathrm{N}+\mathrm{O}=100.0 .1$

(a) Argon bombardment $\left(E \simeq 1.6 \times 10^{-16} \mathrm{~J}\right.$ or $1000 \mathrm{eV}$ )

\begin{tabular}{|c|c|c|c|}
\hline e- Energy & Element & wt.\% & $\begin{array}{c}\text { Pure Kapton, } \\
\text { wt.\% }\end{array}$ \\
\hline $1.6 \times 10^{-16} \mathrm{~J}(1.0 \mathrm{keV})$ & $\mathrm{C}$ & 58.1 & 71.1 \\
& $\mathrm{~N}$ & 8.5 & 7.2 \\
& 0 & 33.4 & 21.6 \\
& & & 71.1 \\
& $\mathrm{C}$ & 66.9 & 7.2 \\
& $\mathrm{~N}$ & 6.5 & 21.6 \\
& 0 & 26.5 & 71.1 \\
& $\mathrm{C}$ & 72.8 & 7.2 \\
& $\mathrm{~N}$ & 6.6 & 21.6 \\
\hline
\end{tabular}

(b) 0xygen bombardment ( $\simeq<4.8 \times 10^{-18} \mathrm{~J}$ or $30 \mathrm{eV}$ )

\begin{tabular}{|c|c|c|c|}
\hline $\mathrm{e}^{-}$Energy & Element & $w t . \$$ & $\begin{array}{c}\text { Pure Kapton, } \\
\text { wt. } \%\end{array}$ \\
\hline $1.6 \times 10^{-16} \mathrm{~J}(1.0 \mathrm{keV})$ & $\begin{array}{l}C \\
N \\
0\end{array}$ & $\begin{array}{r}61.2 \\
7.0 \\
31.8\end{array}$ & $\begin{array}{r}71.1 \\
7.2 \\
21.6\end{array}$ \\
\hline $6.4 \times 10^{-16} \mathrm{~J}(4.0 \mathrm{keV})$ & $\begin{array}{l}C \\
N \\
0\end{array}$ & $\begin{array}{r}70.4 \\
7.1 \\
22.4\end{array}$ & $\begin{array}{r}71.7 \\
7.2 \\
21.6\end{array}$ \\
\hline $2.4 \times 10^{-15} \mathrm{~J}(15.0 \mathrm{keV})$ & $\begin{array}{l}\mathbf{C} \\
N \\
0\end{array}$ & $\begin{array}{r}66.8 \\
8.6 \\
24.6\end{array}$ & $\begin{array}{r}71.1 \\
7.2 \\
21.6\end{array}$ \\
\hline
\end{tabular}


TABLE III. - COMPLEX INDICES OF REFRACTION FROM ELLIPSOMETRY

\begin{tabular}{|c|c|c|c|}
\hline Ion & Sample & $n($ real) & K (imaginary) \\
\hline $\begin{array}{l}0^{+} \\
0^{+} \\
A^{+} \\
A^{+}\end{array}$ & $\begin{array}{l}\text { Sample } 1 \\
\text { Sample } 2 \\
\text { Sample 1 } \\
\text { Position } 1 \\
\text { Sample } 1 \\
\text { Position } 2\end{array}$ & $\begin{array}{l}1.16 \\
2.72 \\
2.4 \pm 0.4 \\
1.0 \pm 0.3\end{array}$ & $\begin{array}{l}-0.22^{\star} \\
-0.34 \\
-0.8 \pm 0.6 \\
+2.2 \pm 0.1\end{array}$ \\
\hline Pris & tine & $0.5 \pm 0.2$ & $+1.9 \pm 0.1$ \\
\hline
\end{tabular}

*Errors for the oxygen bombarded samples are $<0.1$ in both parts of the index of refraction.

TABLE IV. - DERIVED RATES OF REACTION ASSUMING ONLY ION BEAM REACTION

\begin{tabular}{|c|c|c|c|c|}
\hline Date & Ion & $\begin{array}{l}0^{+} \text {fluence, } \\
\mathrm{cm}^{-2}\end{array}$ & $\begin{array}{l}\text { Rate, } \\
\text { g/ } 0^{+} \text {ion }\end{array}$ & Method \\
\hline $\begin{array}{l}11 / 24 / 82 \\
12 / 09 / 82\end{array}$ & $\begin{array}{l}0^{+} \\
0^{+}\end{array}$ & $\begin{array}{l}1.3 \times 10^{18} \\
2.4 \times 10^{17}\end{array}$ & $\begin{array}{l}>2.8 \times 10^{-22} \\
>5 \times 10^{-22}\end{array}$ & $\begin{array}{l}\text { Total loss of } 1 \mathrm{mil} \text { layer } \\
\text { SEM photos }\end{array}$ \\
\hline
\end{tabular}

TABLE V. - DERIVEO RATES OF

REACTION ASSUMING AMBIENT

OXYGEN REACTION

\begin{tabular}{|c|c|c|}
\hline Date & $\begin{array}{l}\text { Therma } 1 \\
\text { fluence }\end{array}$ & $(\mathrm{g} /$ collision $)$ \\
\hline $11 / 24 / 82$ & $\sim 1.9 \times 10^{21}$ & $>2 \times 10^{-25}$ \\
$12 / 09 / 82$ & $\sim 9.4 \times 10^{20}$ & $\geqslant 1 \times 10^{-25}$ \\
\hline
\end{tabular}




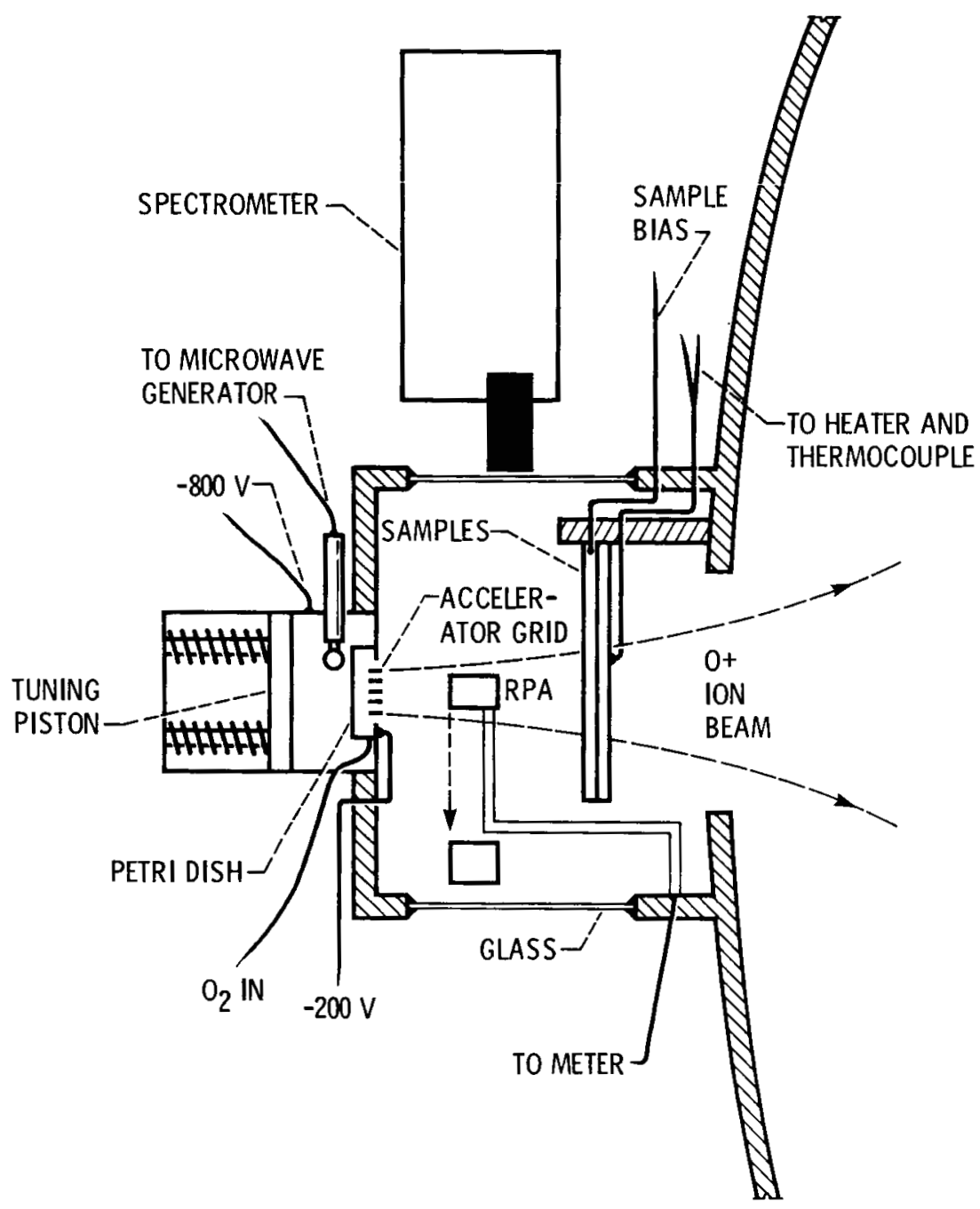

Figure 1. - The experimental setup. 


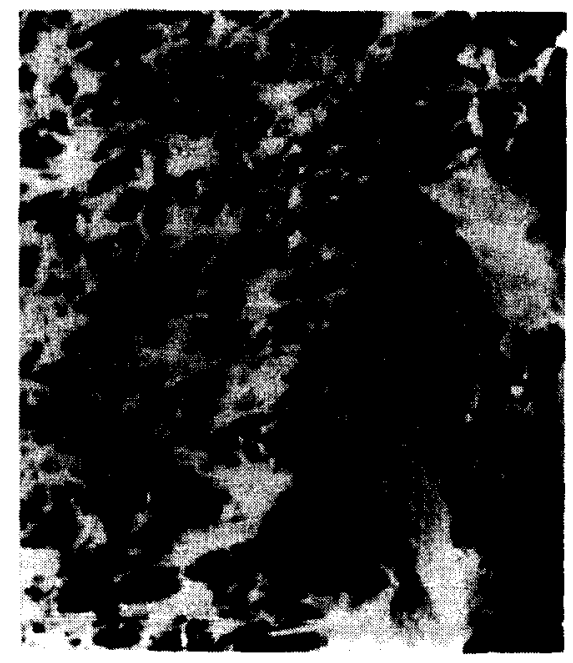

(a) Lewis Research Center $\mathrm{O}^{+}$beam exposure.

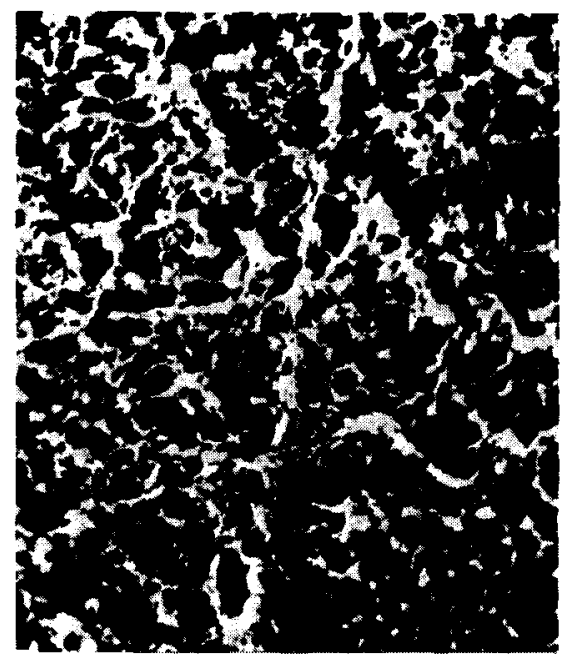

(b) SIS-2 orbital exposure.

Figure 2. - Surface structure of exposed samples. SEM magnification 10,000X. 


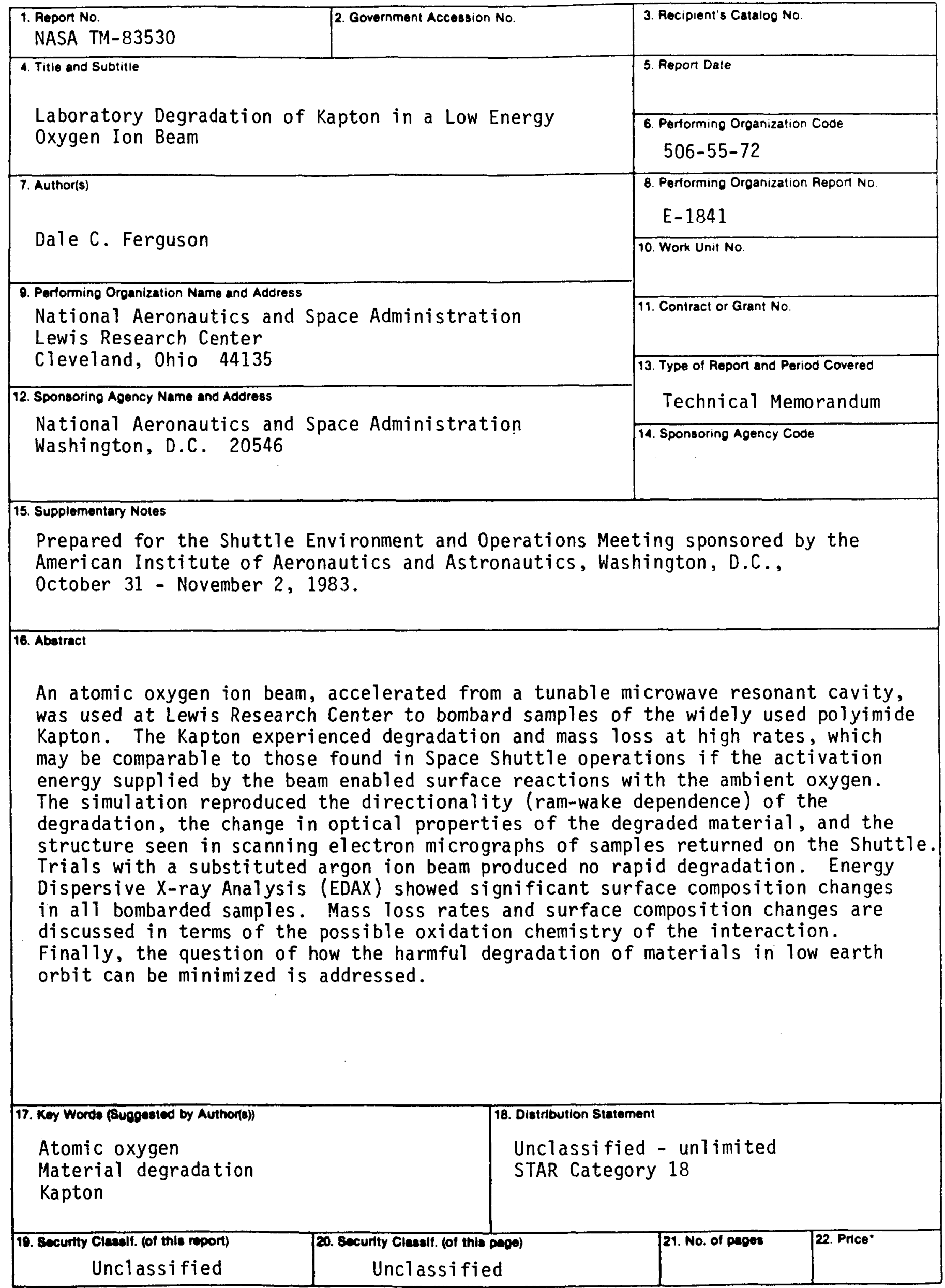

"For by the National Technical Information Service, Springfield, Virginia 22161 